\title{
Entrevista com Giorgio De Marchis e Gian Luigi De Rosa: tradução al di là dell'oceano
}

Francesca Cricelli

Nós, da Cadernos de Literatura em Tradução, decidimos apresentar uma entrevista que passa pelo caminho inverso, ou no contrafluxo do caminho 'de/ para' comumente tomado nas entrevistas feitas com tradutores. Nesta edição, convidamos os professores e tradutores italianos Giorgio De Marchis e Gian Luigi De Rosa para conversarem conosco sobre sua experiência na tradução do português para o italiano. Colhemos o momento do lançamento do livro de ensaios de Haroldo de Campos Traduzione, Transcreazione Saggi pela editora Oèdipus, na Itália, volume organizado por Andrea Lombardi e traduzido por ele junto a Gaetano D’Itria, para conversar com nossos entrevistados também sobre o legado de Haroldo al di là dell'oceano. Para De Marchis, a obra de Haroldo é um autêntico desafio hermenêutico ao qual se deve retornar periodicamente. Já De Rosa nos lembra que através de Haroldo percebe-se que a tradução não é somente a "transposição" de signos verbais, mas também a passagem de uma língua-cultura para outra.

De Rosa traduziu Marcelino Freire, Luiz Ruffato, Adriana Lisboa, Zélia Gattai e Moacir C. Lopes, entre outros. De Marchis traduziu Agualusa, Ruffato, a moçambicana Paulina Chiziane e o poeta português A. M. Pires Cabral. Ambos coordenam o grupo de estudos e pesquisa "Um arquivo ítalo-brasileiro de literatura" com as professoras Lucia Wataghin (USP) e Patricia Peterle (UFSC). Desejamos uma boa leitura! 
A editora italiana Oèdipus publicou, recentemente, o livro Traduzione, Transcreazione Saggi de Haroldo de Campos, com a organização e tradução de Andrea Lombardi e Gaetano D'Itria. Havia alguma recepção sobre o trabalbo tradutório e poético de Haroldo de Campos antes da publicação deste volume? Vocês já tinham alguma proximidade com Haroldo?

Giorgio De Marchis: Haroldo de Campos não era um autor inédito em Itália e intelectuais como Umberto Eco e Piero Boitani já tinham salientado a sua importância. Além disso, em 2005, se publicou L'educazione dei cinque sensi, um volume organizado por Lello Voce, que reunia traduções das suas obras poéticas. O livro organizado por Andrea Lombardi e Gaetano D’Itria tem, porém, o mérito indiscutível de ter reunido os artigos "italianos" de Haroldo, tornando acessível, para um leitor não acadêmico, a faceta crítica e teórica de um poeta extraordinário. Julgo que para qualquer estudioso que se interesse pela cultura brasileira, pela poesia contemporânea, ou pela teoria da tradução, Haroldo de Campos representa um autor incontornável. O meu primeiro contacto com a sua obra se deu na altura em que era estudante, graças à leitura do ensaio Da razão antropofágica. Diálogo e diferença na cultura brasileira. Um autêntico desafio hermenêutico ao qual regresso periodicamente.

Gian Luigi De Rosa: A reflexão tradutória e tradutológica de Haroldo de Haroldo de Campos foi e continua sendo objeto de estudo de muitos estudiosos da tradução e de diferentes tradutores em âmbito lusitanístico. Pessoalmente, considero o tradutor um adaptador que se transforma também em uma espécie de novo autor, porque deve dar uma nova voz àquilo que está traduzindo. A tradução literária não é simplesmente uma "transposição" de signos verbais, é também a passagem de uma língua-cultura para outra língua-cultura e nem sempre é fácil encaixar os detalhes.

Poderíamos dizer, de forma um pouco reduzida, que para Haroldo de Campos a literatura era um espaço de constante ingestão recíproca, entre as linguas e culturas, por isso sua visão da tradução como recriação permanece uma ideia central para os tradutores literários no Brasil, sobretudo no campo da poesia. Há elementos desta visão haroldiana em seus trabalhos como tradutores? Poderiam citar algum exemplo? Vocês também consideram a tradução em si como uma operação de crítica? De que forma?

Giorgio De Marchis: A proposta de Haroldo de Campos é mais um desafio do que um convite. Como é sabido, a reflexão haroldiana sobre a tradução 
poética como prática impossível e, portanto, necessariamente criativa leva a encarar a tradução literária como recriação permanente. Evidentemente, se trata de uma praxis saudável, mas, em Haroldo, essa liberdade criativa do tradutor se exerce a partir dum exercício crítico rigorosíssimo, que abre a tradição, permitindo renovar constantemente o seu legado. As suas traduções poéticas são obras-primas de um artista, sim, mas de um artista dotado de uma erudição portentosa! Do meu ponto de vista, a liberdade criativa atinge esses cumes só quando se sustenta numa erudição prodigiosa. Caso contrário, a criatividade do tradutor se reduz a uma estéril operação de prestidigitação verbal, que não ilumina o texto nem faz com que ecoem nele outras línguas e outras culturas. Como tradutor literário, considero a tradução uma operação crítica, mas encaro a minha liberdade criativa como uma liberdade vigiada.

Gian Luigi De Rosa: A tradução é certamente um momento de reescrita e de recriação em que o objeto e o produto da tradução fundem-se e confundem-se entre o processo de tradução e recriação para poder tornar-se parte integrante do contexto literário e cultural do receptor. $\mathrm{Na}$ minha experiência como tradutor literário sempre procurei um ponto de equilíbrio entre a reescrita e a recriação interlinguística, entre estilo autoral e língua literária, procurando mediar e recosturar os rasgos devidos à distância intercultural e interlinguística. Todavia, nem sempre pude encontrar a alquimia certa e reproduzir em dobro na forma (para mim) satisfatória a voz e o estilo do escritor que traduzi. Consegui encontrar uma chave de reescrita para $A$ ostra e o vento de Moacir C. Lopes, para os romances de Luiz Ruffato, para as coleções de Marcelino Freire e para A namorada, de Zélia Gattai; enquanto o romance que traduzi com maior dificuldade - sobretudo para encontrar o registro adequado à cultura de recepção para que pudesse reverberar as características de estilo originais - foi o livro "Hanói” de Adriana Lisboa.

No que diz respeito à ideia de que a tradução se possa considerar uma operação de crítica, devo dizer que posso considerá-la (a ideia) mais interessante do ponto de vista linguístico-tradutório que do ponto de vista literário-tradutório, já que a escolha lexical de um tradutor ilustra muito claramente sua visão, que se reflete também na recepção literária do texto traduzido.

Gian Luigi, como ocorreu sua passagem da tradução literária para a tradução audiovisual? Ou você atua em ambos os fronts em concomitância? Você considera que seja um trabalho completamente diferente o que se faz com a tradução literária e audiovisual? Há uma presença 
relevante desse trabalho no mercado cinematográfico italiano, ou é algo usado, primariamente, com escopo didático?

Curiosidade. Principalmente curiosidade. Adoro ler romance e assistir a filmes e seriados e gosto de traduzir. Isso no começo era principalmente uma atividade de reflexão tradutológica que aos poucos se tornou uma atividade tradutória prática, porque, na minha opinião, para poder falar de tradução precisa encarar os problemas práticos da quotidianidade da tradução. Comecei traduzindo romances e contos, depois comecei a legendar curtas brasileiros e portugueses. A tradução audiovisual não pode ser considerada como uma disciplina única, porque existem diferentes modalidades tradutórias conforme a tipologia do texto audiovisual e o país onde se realiza o processo. Às vezes pode ser uma questão de moda ou de escolha forçada. Por exemplo, se pensarmos nos filmes documentários, até alguns anos atrás a modalidade mais utilizada era a legendagem, hoje em dia o voice-over é a modalidade mais difusa e mais aceita pelo público mundial.

Quanto ao lado profissional, esse aspecto é mais relevante e mais evidente na tradução audiovisual. A Unisalento Summer School of Audiovisual Translation, que eu dirijo com a colega Francesca Bianchi, prepara para a profissão de legendador e de tradutor audiovisual, providenciando uma competência técnica ao lado da competência tradutória audiovisual. No mercado italiano, não havia muitos filmes brasileiros ou portugueses até alguns anos atrás, mas agora com as plataformas como Netflix, esses produtos estão chegando e começam a precisar de bons tradutores.

Giorgio, num artigo que você escreveu para o blog "Linea di frontiera", encontramos a seguinte declaração: "Quando traduco un libro, ho spesso la sensazione - lo confesso subito, una sensazione assolutamente ridicola e del tutto irrazionale - che il libro in questione sia stato scritto solo per me. Un po' come se stessi traducendo una lettera privata, indirizzata a Giorgio de Marchis"." Você estava naquele momento traduzindo Barroco Tropical, do Agualusa. Nos pareceu uma excelente leitura do modus operandi manter um diário de tradução. Gostaríamos de saber mais sobre esta sua sensação "absolutamente ridícula e irracional", como você diz mas algo verdadeiro quando lido por outro tradutor. Qual é a relação que se instaura entre o texto e

1 Quando traduzo um livro, tenho com frequência a sensação - confesso imediatamente, uma sensação absolutamente ridícula e completamente irracional - que o livro em questão foi escrito somente para mim. É um pouco como se estivesse traduzindo uma carta particular endereçada a Giorgio de Marchis. 
o tradutor, qual o envolvimento possivel? Qual o limite desta entrega? Poderia nos contar mais sobre essa sensação e citar alguns exemplos dos livros que você traduziu?

Na verdade, esse diário de tradução foi escrito a pedido insistente do editor e hoje até me envergonho daquela confissão, precisamente pelo fato de ser "absolutamente ridícula e irracional". Infelizmente, as palavras escritas on-line manent muito mais do que aquelas que se escrevem em papel... De qualquer maneira, sim, a relação que se estabelece com o texto que traduzimos é de uma intimidade absoluta. Duvido que haja leitores mais atentos de um romance do que o seu próprio tradutor, que lê esse livro quatro, cinco vezes e não raro fica dias a fio à volta da mesma frase. No caso do Agualusa, tendo traduzido vários romances dele e tendo conversado várias vezes com o autor sobre os problemas de tradução que os seus textos me colocavam, traduzindo Barroco Tropical eu tinha a sensação de continuar essa conversa e, perante algumas passagens terrivelmente íngremes, de ter caído em armadilhas que eu mesmo tinha sugerido ao autor. Como disse, uma sensação absolutamente ridícula e irracional, mas, quando falei dessa sensação com Agualusa, ele sorriu diabolicamente...

Há algum trabalho de tradução, ou experiência de tradução, que vocês elegeriam como a preferida, e se sim, por quais motivos? Há entre esses trabalhos algum filho que custa reconbecer como seu?

Giorgio De Marchis: A antologia de versos do poeta português A. M. Pires Cabral - Le illegibili pagine dell'acqua (Napoli, 2011) - é uma tradução de que me orgulho bastante, apesar de não me considerar um bom tradutor de poesia. Mas se trata de um livro que eu quis fazer e cuja existência se deve à minha teimosia. Da mesma maneira, a tradução do romance Niketche. Uma história de poligamia, da moçambicana Paulina Chiziane é provavelmente o trabalho que me deu mais prazer como tradutor. Pelo contrário, confesso que há um romance de outro autor (cujo título não vou revelar) que detestei como leitor e que traduzi a contragosto e nas piores condições possíveis. Foi uma tortura e eu estava convencido de que o resultado final fosse vergonhoso, ao ponto que nem queria entregar a tradução ao editor. Por razões misteriosas, o editor ficou muito satisfeito, a tradução foi elogiada pela imprensa, alguns leitores escreveram dando os parabéns ao tradutor e eu continuo sem saber como tudo isso foi possível... 
Gian Luigi De Rosa: Acho que na tradução também vale o ditado que "nunca se esquece o primeiro amor", assim foi pra mim. Tenho ainda uma lembrança muito forte do período em que traduzi $A$ ostra e o vento de Moacir C. Lopes. Aquelas emoções nunca mais voltaram com as outras traduções.

\section{Quais leituras e atividades vocês reputam fundamentais para um tradutor em formação?}

Giorgio De Marchis: A teoria da tradução tem uma bibliografia crítica inesgotável, com algumas obras que se consideram clássicas e, diria eu, de leitura imprescindível. Pessoalmente, acho os textos de Antoine Berman e André Lefevere sempre muito interessantes e estimulantes. Mas a sua pergunta me obriga a pensar num tradutor em formação (apesar de todos nós sermos sempre tradutores em formação perante um novo texto). De qualquer maneira, vou tentar responder: se alguém tivesse a possibilidade de ler todos os livros de teoria da tradução - estamos perante uma hipótese impossível, evidentemente - esse leitor, mesmo assim, não teria nenhuma garantia de ser um bom tradutor perante um texto literário. Porém, também não vejo como um bom tradutor - não um tradutor, um bom tradutor - possa não ter conhecimentos teóricos. E isso porque a teoria da tradução não dá respostas, mas, pelo menos, nos permite ver as perguntas que os textos que temos que traduzir nos colocam. Um tradutor sem competência teórica é um tradutor que simplesmente não ouve essas perguntas e, portanto, não responde.

Gian Luigi De Rosa: Leituras: Umberto Eco e Peeter Torop, para a tradução literária, e Gambier, Gottlieb e Díaz Cintas, para a tradução audiovisual; a esses autores acrescento os dois trabalhos de Gaetano Berruto dedicados ao processo tradutório do ponto de vista sociolinguístico.

Atividades: traduzir em si é uma atividade que ajuda muito, mas, no começo da carreira de tradutor literário e audiovisual, é fundamental a presença e a ajuda de um editor, no caso literário, e de um diretor de legendagem ou de dublagem, na tradução audiovisual, experientes para poder aprender a profissão de tradutor do ponto de vista prático.

O que ainda não traduziram e desejam, profundamente, fazer?

Giorgio De Marchis: Esta resposta é fácil: Eça de Queirós.

Gian Luigi De Rosa: O próximo livro e o próximo filme. 
Além de docentes e tradutores, que já é muito, vocês também escrevem, ainda que secretamente, ou não, poesia e/ ou prosa ficcional? Escondem algo na gaveta?

Giorgio De Marchis: Deve haver algo esquecido e perdido nalguma gaveta lá em casa. De resto, quem não tem esqueletos no armário? Felizmente, encontra-se tudo muito bem guardado e, que eu saiba, nesses papéis não deve haver nenhum poema. O esboço talvez de alguma prosa muito ingênua e que, garanto, não vale a pena ser lida.

Gian Luigi De Rosa: Na verdade, não escondo um passado literário, publiquei dois livros de poemas e um conto e tenho uma antologia de contos guardados na gaveta. Todavia, quando comecei a me dedicar totalmente à pesquisa científica, me dei conta que minha energia "escritória" não dava para os dois mundos da escrita e deixei de lado a minha escrita ficcional, mas só de lado, quem sabe um dia.

Quais são os projetos com que vocês trabalham que envolvam o Brasil e a Itália? Podem nos contar algo sobre o grupo de pesquisa "Um arquivo Ítalo-Brasileiro" presente na Abralic?

Giorgio De Marchis: “Um arquivo Ítalo-Brasileiro” é um simpósio organizado junto com Lucia Wataghin e Patricia Peterle (e na sua primeira edição também com Gian Luigi De Rosa) que pretende ser um espaço de encontro entre italianistas e brasilianistas para debater e discutir as relações culturais ítalo-brasileiras na contemporaneidade. A primeira edição do simpósio foi muito interessante e julgo que a segunda edição será igualmente enriquecedora. No que me diz respeito, neste momento, estou tentando finalizar uma série de trabalhos e alguns deles envolvem o Brasil, claro. O projeto talvez mais interessante é sobre a recepção da literatura brasileira na Itália oitocentista. Apresentei já os primeiros resultados nalguns artigos e colóquios, mas estou convencido de que há ainda muito trabalho por fazer.

Gian Luigi De Rosa: Além do Grupo de pesquisa "Um arquivo Ítalo-Brasileiro", faço parte de uma rede internacional de pesquisa que analisa o ensino do Português Brasileiro no estrangeiro e estou tentando organizar uma linha direta entre um circuito de universidades italianas e brasileiras sobre o ensino do português e a prática tradutória com intercâmbios de alunos e professores. 
Giorgio De Marchis: Estava prevista para o mês de agosto porque tencionava participar na ABRALIC, onde coordeno a segunda edição do simpósio a que você fez referência na pergunta anterior. Infelizmente, tive que renunciar a essa viagem por razões alheias à minha vontade. De qualquer maneira, em finais de setembro está previsto que eu participe no congresso da ABRAPLIP, que este ano vai decorrer em Curitiba, e antes terei a possibilidade de estar num colóquio sobre o romance histórico oitocentista em língua portuguesa organizado pela USP e pela UNESP.

Gian Luigi De Rosa: Espero que em breve. 


\section{Dois poemas de Pires Cabral traduzidos por Giorgio De Marchis}

\section{OS CIGANOS}

Dizem que vêm da Europa Central. Eu vejo-os vir dos lados de Grijó em lassa caravana.

Debaixo da carroça trota a coelheira, aproveitando a sombra débil e ambulante.

Sentado na boleia, as rédeas na mão morena descuidadas, um homem cisma, confia do caminho ao macho lento a decisão. Outros homens a pé e mulheres novas entretêm de riso a caminhada espessa. Logo após, sobre os burros, os pertences. Alguns velhos também, já cansados de tudo, tiram partido do precário trote. As crianças de peito sugam em sonolenta teima as elásticas tetas sacudidas, mas alvas e redondas.

Os mais velhitos caminham repartidos em pequenas e lúdicas manadas, dando às hortas laterais breves saltos furtivos.

Toda esta gente é morena e tem fala cantada, levanta para mim doces olhos castanhos.

Dizem que vêm da Europa Central, de uma raça sem chão, e aqui procura, de insultos rodeada, cumprir a sua luta, seu degredo e sua primitiva vocação.

Dizem que os ciganos desenterram animais defuntos de alguma enfermidade menos limpa e neles cravam dentes de fome milenária.

Dizem que as mulheres estão na intimidade das estrelas e a troco de uns mil-réis leem nas mãos destinos coloridos. Dizem que roubam quintais e assaltam capoeiras, e os aldeões, em pânico secreto, 
os expulsam com voz impiedosa e decidida mão

das cercanias do seu chão governado.

Dizem que enganam os incautos campónios

em negócios sempre escuros de animais,

em que fazem passar por uma estampa

o mais escalavrado e cego dos cavalos.

Dizem que na vila, ao desfazer das feiras,

têm por costume, depois de embriagados,

trocar com as bengalas possantes e vistosas

pancadaria rija, de que morrem.

Dizem que vivem estranhos dramas passionais.

Dizem que não têm deus e que se casam

lançando ao ar jubilosos chapéus.

Dizem tudo isso dos ciganos. Eu não sei.

Vejo-os vir dos lados de Grijó

e estão todos de frente para mim

e parecem-me gente - nada mais.

\section{GLI ZINGARI}

Si dice che vengano dall'Europa Centrale. Io li vedo venire dalle parti di Grijó in stanca carovana.

Sotto la carrozza trotta il bracchetto, sfruttando l'ombra debole e ambulante.

Seduto in serpa, le redini nella mano bruna

abbandonate, un uomo pensa, affida

del cammino al lento mulo la scelta.

Altri uomini a piedi e donne giovani

distraggono col riso la densa camminata.

Subito dietro, sugli asini, gli averi.

Qualche vecchio poi, ormai stanco di tutto, approfitta del precario trotto. I bambini

in braccio succhiano con assonnata ostinazione

le elastiche tette scosse, ma rotonde e bianche.

I più grandini camminano divisi 
in piccoli manipoli giocosi, facendo

negli orti laterali brevi salti furtivi.

Tutta questa gente è bruna e ha un parlar cantato, alza verso di me dolci occhi castani.

Si dice che vengano

dall'Europa Centrale, da una razza senza terra,

e qui cerca, di insulti circondata,

di compiere la sua lotta, il suo esilio

e la sua antica vocazione.

Si dice che gli zingari dissotterrino animali morti

di qualche malanno poco chiaro

e vi affondino denti di fame millenaria.

Si dice che le donne siano intime

delle stelle e in cambio di pochi spiccioli

leggano nelle mani destini colorati.

Si dice che rubino orti e assaltino pollai,

e gli abitanti, in panico segreto,

li scaccino con impietosa voce e mano ferma

dai dintorni della loro terra governata.

Si dice che ingannino gli incauti contadini

in affari sempre oscuri di animali,

in cui rifilano come purosangue

il più sgangherato e cieco dei cavalli.

Si dice che in paese, quando sgombrano le fiere, siano soliti, dopo essersi ubriacati, scambiarsi con robusti e vistosi bastoni

botte da orbi, di cui muoiono.

Si dice che vivano strani drammi passionali.

Si dice che non abbiamo un dio e si sposino

lanciando in aria cappelli giubilanti.

Si dice tutto questo degli zingari. Io non so.

Li vedo venire dalle parti di Grijó

e sono tutti qui davanti a me

e mi sembrano gente - niente più . 
SÃO MIGUEL DA PENA

Viveu gente em São Miguel, que depois aqui morreu

e se fez sepultar nesta encruzilhada de ventos.

De ciência alguma não te ufanes, enquanto não puderes explicar por quê exactamente aqui, neste tão ermo, líquido lugar, se te soltam e abraçam pensamentos

como inimigos que se abraçam.

\section{SÃO MIGUEL DA PENA}

Visse gente a São Miguel, che poi qui morrì e si fece seppellire in questo incrocio di venti.

Di scienza alcuna non vantarti, finché non potrai spiegare perché proprio qui, in così ermo, liquido luogo, ti si sciolgono e confondono pensieri come nemici che si abbracciano. 


\section{Início de A Ostra e o Vento, de Moacir Lopes, traduzido por Gian Luigi De Rosa}

Velho Daniel apanhou o caderno com mãos trêmulas, olhou para as gaivotas circundando a torre do farol, temeu os catraios de asas escuras descendo dos picos, gritou por Marcela, Marcela, Marcela... e só então sentiu que estava deserta a ilha dos Afogados. Nem conseguiu ler a página que o vento deixara aberta:

Saulo é tão importante que está tomando conta de mim inteiramente. Nem posso mais entregar-me aos afazeres normais, auxiliar papai ou Roberto, que logo escuto seu chamado e corro sempre para ele. Vejo-o em todos os cantos da ilha, sinto-o em todas as partes de meu corpo, e espero que os mumbebos, de asas abertas, gritem do coral as horas que farão noite e possa correr para entregar-me a ele na praia. Já não importa que pai ou Roberto estejam ou não dormindo, já nem cuido que presenciem nossa posse.

Tal é a ânsia de Saulo por mim e de mim por ele, que o vejo em tudo na ilha. Impregnado na água do córrego, e quando por ela caminho sinto-o penetrando pelo meu corpo. No toque de sinos que o vento provoca nas fendas dos picos ele me completa de sons que se materializam como se me beijassem os ouvidos, a boca, os olhos, os seios e os cabelos, então sinto vontade de abrir-me ao vento e deixar que Saulo penetre inteiramente em mim.

Tenho que fazer este registro enquanto distingo pelo menos que o vento é ainda vento, o córrego é ainda córrego, o mar ainda mar, que as aves são aves ainda, porque se continuar assim em poucos dias tudo será Saulo e não distinguirei mais anda e nas páginas deste caderno só repetirei seu nome...

Il vecchio Daniel prese il quaderno con mani tremule, guardò i gabbiani intorno alla torre del faro, ebbe paura delle fregate dalle ali scure che planavano dai dirupi, gridò il nome di Marcela, Marcela Marcela... e solo in quel momento si accorse che l'isola degli Affogati era deserta. Non riuscì neanche a leggere la pagina che il vento aveva lasciato aperta:

Saulo è cosi importante che si sta impossessando totalmente di me. Néposso dedicarmi alle solite faccende, aiutare papà o Roberto, che subito sento il suo richiamo e corro da lui. Lo vedo in tutti gli angoli dell'isola, lo sento in tutte le parti del mio corpo, e aspetto che i cormorani, le ali aperte, annuncino dai coralli l'arrivo del buio e io possa correre alla spiaggia per offrirmi a lui. Ormai non m'importa che papà o Roberto dormano o no, né che possano assistere ai nostri incontri.

Tanto è il desiderio di Saulo per me, ed il mio per lui, che lo vedo in tutta l'isola. Impregnato nell'acqua del ruscello, e quando l'attraverso lo sento penetrare nel mio corpo. Nel rintocco di campane che il vento provoca nelle fessure dei picchi lui mi completa di suoni che si materializzano come se mi baciassero le orecchie, la bocca, gli occhi, i seni, i capelli, allora sento il bisogno di aprirmi al vento e lasciare Saulo entrare tutto in me. 
184 Francesca Cricelli. Entrevista com Giorgio De Marchis e Gian Luigi De Rosa: traducão al di là dell'oceano

Devo tenere questo diario fin quando distinguerò almeno che il vento è ancora vento, il ruscello ancora ruscello, il mare ancora mare, che gli uccelli sono uccelli ancora, perché se continua cosi, in pochi giorni, tutto sarà Saulo e non distinguerò più niente e nelle pagine di questo quaderno ripeterò solo il suo nome... 